\title{
Wogonoside inhibits TNF receptor-associated factor 6 (TRAF6) mediated-tumor microenvironment and prognosis of pancreatic cancer
}

\author{
Hui Huang ${ }^{1}, \mathrm{Xia} \mathrm{Li}^{2}$, Li Yu${ }^{1}$, Ling Liu ${ }^{3}$, Hongwei Zhu ${ }^{1}$, Wei $\mathrm{Cao}^{4}$, Zhongling $\mathrm{Sun}^{4}$, Xiao $\mathrm{Yu}^{1}$ \\ ${ }^{1}$ Department of Hepatopancreatobiliary Surgery, The Third Xiangya Hospital, Central South University, Changsha, China; ${ }^{2}$ Department of \\ Endocrinology, The Third Xiangya Hospital, Central South University, Changsha, China; ${ }^{3}$ Department of Cardiology, Second People's Hospital of \\ Hunan Province, Hunan University of Chinese Medicine, Changsha, China; ${ }^{4}$ Xiangya School of Pharmaceutical Sciences, Central South University, \\ Changsha, China \\ Contributions: (I) Conception and design: H Huang, X Li, X Yu; (II) Administrative support: None; (III) Provision of study materials or patients: \\ None; (IV) Collection and assembly of data: H Huang, X Li, L Yu, L Liu, W Cao; (V) Data analysis and interpretation: H Huang, H Zhu, L Liu, W \\ Cao, Z Sun; (VI) Manuscript writing: All authors; (VII) Final approval of manuscript: All authors. \\ Correspondence to: Xiao Yu. Department of Hepatopancreatobiliary Surgery, The Third Xiangya Hospital, Central South University, Changsha \\ 410013, China. Email: xiaoyuxybio@163.com.
}

Background: Pancreatic cancer (PC) is one of the worst prognostic cancers. Here, we probed the anticancer activity of wogonoside (Wog), a flavonoid isolated from Scutellaria baicalensis Georgi, on PC, as well as potential molecular mechanism.

Methods: Following Wog stimulation, the viability, proliferation, apoptosis, stem cell-like transition, and mesenchymal transition were detected in PC cells. Bioinformatics analysis was used to identify possible signaling pathways involved in the anti-PC activity of Wog. Tumor necrosis factor (TNF) receptorassociated factor 6 (TRAF6) was overexpressed and TRAF6 activator IL-1 $\beta$ was used in PC cells to confirm whether Wog exerted anti-PC activity via modulating TRAF6. In vivo, an experiment was conducted to further confirm our supposition.

Results: Wog inhibited PC cell proliferation, promoted cell apoptosis, limited PC cell stem celllike transition and mesenchymal transition. TNF signaling pathway was activated in PC. Besides, Wog inactivated TRAF6/nuclear factor-kappa B (NF- $\kappa \mathrm{B}) / \mathrm{p} 65$ pathway in PC cells. TRAF6, vascular cell adhesion molecule-1 (VCAM1), CD44, and matrix metalloproteinase 14 (MMP14) expressions were upregulated in PC tissues and negatively correlated with PC survival and prognosis. Finally, Wog suppressed TRAF6 overexpression-induced PC cell stem cell-like transition and mesenchymal transition in vitro and tumor growth in vivo.

Conclusions: Wog exerted anti-cancer activity on PC and suppressed the TRAF6 mediated-tumor microenvironment of PC, thereby regulating PC's prognosis.

Keywords: Pancreatic cancer (PC); Wogonoside; TNF receptor-associated factor 6 (TRAF6)/nuclear factorkappa B (NF-кB)/p65 pathway; stem cell-like transition; mesenchymal transition

Submitted Jul 29, 2021. Accepted for publication Sep 02, 2021.

doi: $10.21037 / \mathrm{atm}-21-4164$

View this article at: https://dx.doi.org/10.21037/atm-21-4164

(c) Annals of Translational Medicine. All rights reserved. 


\section{Introduction}

Pancreatic cancer $(\mathrm{PC})$ is a common digestive system cancer with a high mortality rate (1). However, in 2020, there were approximately 57,600 newly diagnosed patients and 47,050 deaths in the United States (2). Considering the 5 -year survival rate of $\mathrm{PC}$ was less than $5 \%, \mathrm{PC}$ is considered one of the worst prognostic malignant cancers (3). Low early diagnosis rates, high cancer recurrence, metastasis rates, and energetic drug resistance are all responsible for the poor prognosis of PC $(3,4)$. Recent years, increasing attention was given to the tumor microenvironment of $\mathrm{PC}$ $(5,6)$. It has been verified that the PC microenvironment is essential for PC development via the modulation of PC cell proliferation, cancer cell stem-like transition, and epithelial-mesenchymal transition (EMT), as well as angiogenesis/lymphangiogenesis (5). The unsatisfactory results of PC therapy could also be partially attributed to the microenvironment (6). Exploring the new therapeutic method targeting the PC microenvironment is believed to have significant value for PC treatment. However, little drugs targeting tumor microenvironment have been used in clinic to treat $\mathrm{PC}$ until now.

Wogonoside (Wog, $\mathrm{C}_{22} \mathrm{H}_{20} \mathrm{O}_{11}$, CAS number: 51059$44-0$, Figure $1 A, 1 B)$, a flavonoid, is the main bioactive ingredient isolated from the root Scutellaria baicalensis Georgi (7). Lots of literature reported the pre-clinical anticancer activity of Wog (7-9). It is demonstrated that Wog suppresses the growth and metastasis of prostate cancer (8) and endometrial cancer (9), as well as promotes the apoptosis of gastric cancer (10), osteosarcoma (11), and non-small cell lung cancer (12). Some literature reported that Wog showed anti-cancer activity via modulating the tumor microenvironment. For instance, Sun et al. (13) reported that Wog slowed down colitis-related colorectal tumorigenesis and colon cancer development in the inflammatory microenvironment through inactivating the nuclear factor-kappa B (NF-kB) pathway. Wang et al. (14) demonstrated that Wog inhibited cutaneous squamous cell carcinoma via reducing EMT/invasion and cancer stemlike transition. Until now, no information could be searched on the anti-cancer activity of Wog on PC, especially its association with PC microenvironment.

Tumor necrosis factor receptor-associated factor 6 (TRAF6) is an E3 ubiquitin ligase (15). As an adaptor protein, TRAF6 takes part in the modulation of many cellular biology processes via altering multiple cellular signaling pathways in cells, including the $\mathrm{NF}-\kappa \mathrm{B}$ pathway (16). The high expression of TRAF6 has been shown in many types of human cancers, including PC $(17,18)$. Rong et al. (18) discovered that TRAF6 regulated gene expression involving PC cell growth, apoptosis, and migration. Besides, earlier literature revealed that TRAF6 contributed to melanoma progression via promoting fibroblasts to cancer-associated fibroblasts' transition in the tumor microenvironment (19).

In the current research, we investigated the antiproliferation, pro-apoptosis, anti-stem cell-like transition, and anti-mesenchymal transition activities of Wog on PC cells. We analyzed whether Wog exerted anti-cancer activity on $\mathrm{PC}$ via modulating the TRAF6/NF- $\mathrm{kB} / \mathrm{p} 65$ pathway by combining bioinformatics analysis. The discoveries made in our research will provide experimental evidence for understanding the beneficial effect of Wog on PC therapy.

We present the following article in accordance with the ARRIVE reporting checklist (available at https://dx.doi. org/10.21037/atm-21-4164).

\section{Methods}

\section{Bioinformatics analysis}

The websites https://www.aclbi.com and https://portal. gdc.cancer.gov were used for bioinformatics analysis. First, to identify the factors influencing PC progression, the differential expressions of mRNA were analyzed between 178 PC samples in the TCGA database and 332 normal samples (including 4 para-cancerous samples in the TCGA database and 328 non-diseased tissue sites from nearly 1,000 individuals) by using the Limma package (version 3.40.2) of R software. Gene Ontology (GO) analysis and Kyoto Encyclopedia of Genes and Genomes (KEGG) Enrichment analysis were conducted to confirm potential targets' underlying functions further. Then, to compare TRAF6, VCAM1, CD44, and MMP14 expression differences between normal tissues and PC tissues, the tumoral and normal RNA-seq data of 178 patients suffering from PC were downloaded from the Genomic Data Commons (GDC) data portal (TCGA). Other 154 data of normal tissues were obtained from the GTEx V8 release version (http://gtexportal.org/home/datasets). $\mathrm{R}$ software (version 4.0.3) was conducted for statistical analyses. Subsequently, to analyze the relationship between TRAF6 (or VCAM1, CD44, or MMP14) expression and overall survival probability of PC patients, the raw counts of RNA-sequencing data (level) and corresponding clinical 
A

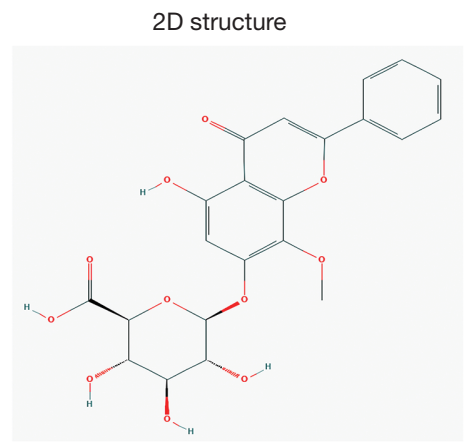

Wogonoside MW: $460.4 \mathrm{C}_{22} \mathrm{H}_{20} \mathrm{O}_{11}$

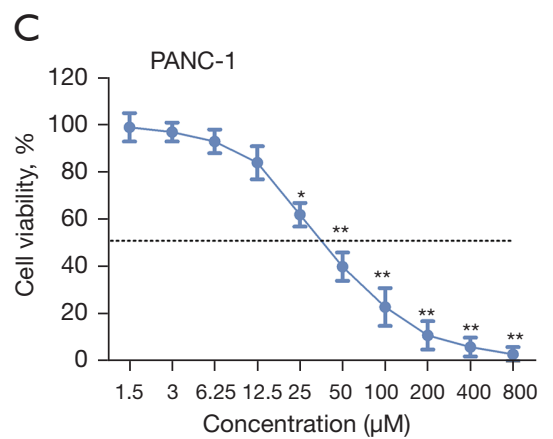

B

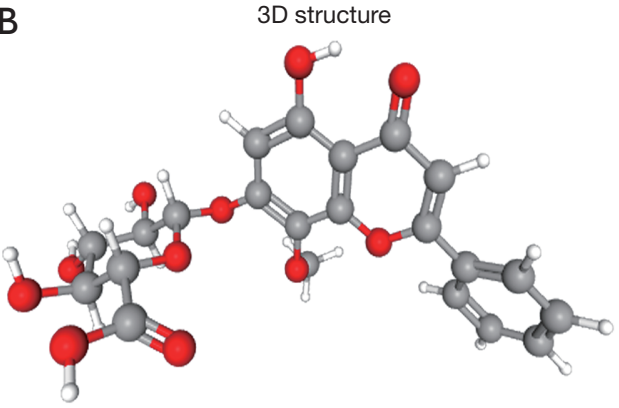

D

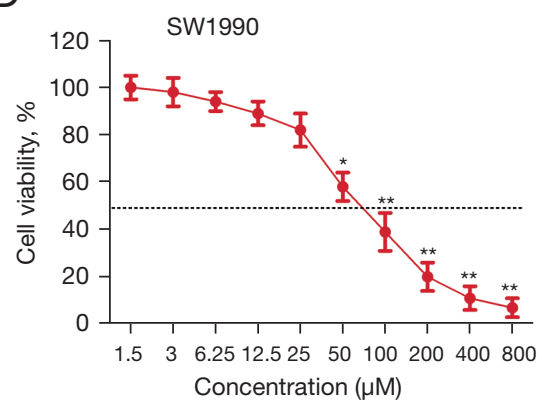

Figure 1 Structure of Wog and Wog inhibited PC cells viabilities. (A,B) The 2D and 3D structure of Wog. (C,D) PANC-1 and SW1990 cells were stimulated by $1.5-800 \mu \mathrm{M}$ Wog; a CCK-8 assay detected cells viabilities. ${ }^{*} \mathrm{P}<0.05$ or ${ }^{* *} \mathrm{P}<0.01$ vs. $1.5 \mu \mathrm{M}$ Wog stimulation group. PC, pancreatic cancer.

information on PC patients were obtained from TCGA. Kaplan-Meier survival analysis with log-rank test was performed to compare the survival difference between high and low expression groups. The predictive accuracy of each gene and risk score was compared via TimeROC analysis. Finally, to confirm the factors affecting the prognosis of PC patients, univariate and multivariate Cox regression analysis was conducted to build a nomogram using the online database (https://www.aclbi.com) by selecting $178 \mathrm{PC}$ samples through setting the parameters [Gene list (TRAF6, VCAM1, CD44, MMP14), clinicopathologic factors (Age, pN stage, pTNM stage, Grade, and Radiation therapy)]. The forest was used to display the $\mathrm{P}$ value, hazard ratio (HR), and 95\% CI of each variable through the 'forestplot' $\mathrm{R}$ package. A nomogram predicted the 1-year survival. The study was conducted in accordance with the Declaration of Helsinki (as revised in 2013).

\section{Cell culture}

PANC-1 and SW1990 cells were supplied by the American Type Culture Collection (ATCC, VA, USA). Cells were grown in Dulbecco's Modified Eagle Medium (DMEM, Procell Inc., Wuhan, China) with the addition of $10 \%$ fetal bovine serum (FBS, Hyclone, UT, USA) and 1\% penicillinstreptomycin solution (Sigma-Aldrich, MO, USA). Culture flasks were placed in a humidified incubator with $5 \% \mathrm{CO}_{2}$ at $37^{\circ} \mathrm{C}$. Wog (purity $>95 \%$ ) was bought from Sigma-Aldrich (No. SMB00081) and dissolved in dimethyl sulfoxide (DMSO).

\section{Cell viability assay}

Cell counting kit-8 (CCK-8) was obtained from MedChemExpress (No. HY-K0301, NJ, USA). PANC1 and SW1990 cells were cultivated into 96-well plates with a density of $1 \times 10^{4}$ cells per well. After $12 \mathrm{~h}$ of culture in the incubator, 1.5-800 $\mu \mathrm{M}$ Wog was added into the culture medium for $24 \mathrm{~h}$. Then, $10 \mu \mathrm{L}$ CCK-8 solution was supplemented into the culture medium for $1-4 \mathrm{~h}$. The absorbance at $450 \mathrm{~nm}$ (OD value) was measured using a microplate reader (Bio-Tek Inc., MO, USA). Cell viability (\%) was calculated by OD values of 1.5-800 $\mu \mathrm{M}$ Wog stimulation groups $/ 1.5 \mu \mathrm{M}$ Wog stimulation group $\times 100 \%$. 


\section{Cell apoptosis assay}

One Step TUNEL Apoptosis Assay Kit was purchased from Beyotime Biotechnology (No. C1089, Shanghai, China). $1 \times 10^{3}$ PANC-1 and SW1990 cells were cultivated in the cover slide for $12 \mathrm{~h}$. Then, 25, 50, or $100 \mu \mathrm{M}$ Wog was added into the culture medium for $24 \mathrm{~h}$. Followed by PBS rinsing, 4\% paraformaldehyde fixing, and PBS rinsing cells were incubated with $50 \mu \mathrm{L}$ TUNEL solution for $1 \mathrm{~h}$ at $37{ }^{\circ} \mathrm{C}$. DAPI was used to dye the nucleus. Then, cells were rinsed with $\mathrm{PBS}$, and the results were obtained via fluorescence microscope (excitation $550 \mathrm{~nm}$ and emission $570 \mathrm{~nm}$, Olympus, Japan). The percentage of apoptotic cells was counted.

The apoptosis of PANC-1 and SW1990 cells was also analyzed by flow cytometry. After different treatments, cells were harvested and re-suspended. Then, cells were performed Annexin V-fluorescein isothiocyanate/propidium iodide (PI) staining for $15 \mathrm{~min}$ in the dark. The percentage of apoptotic cells was evaluated by a FACSCalibur Cytometer (Becton Dickinson, USA).

\section{Cell transfection}

The full-length sequence of TRAF6 was inserted into the pcDNA3.1 plasmid to overexpress TRAF6 in PANC-1 cells (Invitrogen, CA, USA). Cell transfection was performed using Lipofectamine 2000 Reagent (Invitrogen) in line with the manufacturer's instruction.

\section{Cell sphere assay}

$3 \times 10^{4}$ transfected or non-transfected PANC-1 and SW1990 cells were cultivated into a 24-well plate and stimulated by Wog for $24 \mathrm{~h}$. Then, cells in each group were harvested using trypsin-EDTA, washed with PBS, resuspended as single-cell suspension, and cultured into a plate pre-coated with poly-HEMA. After 7 days, the number and diameter of cell spheres were obtained under an inverted light microscope (Nikon, Japan).

\section{ELISA}

$3 \times 10^{4}$ PANC-1 and SW1990 cells were cultivated into a $24-$ well plate and stimulated by 25,50 , or $100 \mu \mathrm{M} \mathrm{Wog}$ for $24 \mathrm{~h}$. Then, the culture supernatant of each group was collected. The concentrations of IL- 6 , TNF- $\alpha$, and IL- $1 \beta$ in culture supernatant were detected using Human IL-6 ELISA Kit
(BMS213HS), Human TNF- $\alpha$ ELISA Kit (BMS223HS, Invitrogen), and Human IL-1 $\beta$ ELISA Kit (RAB0273, Sigma-Aldrich), respectively.

\section{Western blotting}

Total proteins in cells were collected using cell lysis buffer (Beyotime Biotechnology). Bradford Protein Assay Kit (Beyotime Biotechnology) was used for measuring proteins concentration. Western blotting was conducted using a similar method described in the earlier literature. Anti-proliferating cell nuclear antigen (PCNA) antibody (\#13110), anti-p21 antibody (\#2947), anti-SOX2 antibody (\#3579), anti-N-cadherin (N-cad) antibody (\#13116), anti-P65 antibody (\#8242), anti-P65 ${ }^{5336}$ antibody (\#3033), anti-TAK1 (\#5206), anti-phospho-IKK $\beta$ (ser180, \#2697), anti-IKK $\beta$ (\#8943) and anti-GAPDH antibody (\#5174) were supplied by Cell Signaling Technology (MA, USA). AntiTRAF6 antibody (ab33915), anti-vascular cell adhesion molecule-1 (VCAM1) antibody (ab134047), anti-CD44 antibody (ab189524) and anti-matrix metalloproteinase 14 (MMP14) antibody (ab51074) were supplied by Abcam Biotechnology (MA, USA). Signals of proteins were visualized through enhanced chemiluminescence technique. The relative protein expressions were calculated using Image J software.

\section{Animal experiment}

Fifteen 6- to 8-week-old BALB/c nude mice (male, 20-25 g) were housed in an aseptic environment at $26-28^{\circ} \mathrm{C}$ with free access to food and water. After feeding in our facility for 1 week, the mice were weighed and randomly divided into control, TRAF6 and TRAF6+Wog groups, with 5 mice in each group. For mice in the Control group, $1 \times 10^{6}$ PANC- 1 cells were inoculated into the left axillary area. For mice in the TRAF6 group and TRAF6+Wog group, $1 \times 10^{6}$ PANC- 1 cells with TRAF6 over-expression were inoculated into the left axillary area. $80 \mathrm{mg} / \mathrm{Kg}$ Wog was given daily for mice in the TRAF6+Wog group by gastric lavage. According to the formula, the long (a) and short (b) diameters of the tumors were measured every 5 days after Day 4 for computed tumor volume according to the formula: $\mathrm{ab}^{2} / 2$. After 30 days, all mice were sacrificed under anesthesia, and the tumor specimens were collected, weighed, and fixed in a $10 \%$ formalin solution. All treatments and analyses were performed blinded to the experimental conditions of the animals during the allocation, the conduct of the 
experiment, the outcome assessment, and the data analysis. Experiments were performed under a project license [No.: SYXK (Xiang) 2017-0002] granted by the Third Xiangya Hospital, Central South University, in compliance with China guidelines for the care and use of animals. A protocol was prepared before the study, but was not registered.

\section{Immunobistochemistry}

Formalin-fixed and paraffin-embedded tumor specimens were cut in $6 \mu \mathrm{m}$ sections. Following deparaffinization and hydration, the sections were treated with $0.01 \mathrm{M}$ sodium citrate (PH 6.0) solution in the microwave for 10 minutes to antigen retrieval. Then, the sections were permeabilized with $0.2 \%$ Triton X-100 solution for $15 \mathrm{~min}$, and quenched endogenous peroxidase activity by $3 \%$ hydrogen peroxide solution for $15 \mathrm{~min}$. $5 \%$ normal goat serum was used to prevent non-specific binding. After that, the sections were incubated with anti-TRAF6 antibody, anti-VCAM1 antibody, anti-CD44 antibody, or anti-MMP14 antibody overnight, and horseradish peroxidase-conjugated secondary antibody (Bio-Rad Laboratories, CA, USA) at $37{ }^{\circ} \mathrm{C}$ for $30 \mathrm{~min}$. Antibody binding was visualized using diaminobenzidine solution. Hematoxylin solution was used to stain the nucleus. The results were observed using light microscopy at $400 \times$ magnification, and the percentages of positive cells (\%) were measured.

\section{Statistical analysis}

Prism 6.0 software was used for statistical analysis from three repeated experiments. Data were represented as mean \pm standard deviation (SD). One way-ANOVA and two wayANOVA were conducted for calculating $\mathrm{P}$ value, with a significance level of $\mathrm{P}<0.05$.

\section{Results}

\section{Wog inbibited PC cell proliferation and promoted cell apoptosis}

First, after 1.5-800 $\mu \mathrm{M}$ Wog stimulation, the viability, apoptosis, and proliferation of PANC-1 and SW1990 cells were detected. Figure $1 C, 1 D$ showed that Wog stimulation reduced the viabilities of PANC-1 and SW1990 cells in a concentration-dependent manner $(\mathrm{P}<0.05$ or $\mathrm{P}<0.01)$. The Wog concentrations of 25,50 , and $100 \mu \mathrm{M}$ were selected for further experiments. Figure $2 A$ showed that different concentrations of Wog stimulation significantly promoted PANC-1 and SW1990 cell apoptosis, as shown by the increased red fluorescence in Wog treatment groups $(\mathrm{P}<0.05$ or $\mathrm{P}<0.01)$. Figure $2 B$ presented that Wog stimulation lowered the PCNA protein level, but raised the p21 protein level in PANC-1 and SW1990 cells in a dose-dependent pathway $(\mathrm{P}<0.05$ or $\mathrm{P}<0.01)$. Additionally, the apoptosis of PANC-1 and SW1990 cells was also confirmed by flow cytometry (Figure $2 C ; \mathrm{P}<0.05$ or $\mathrm{P}<0.01$ ). These outcomes suggested that Wog inhibited PC cell proliferation and promoted cell apoptosis.

\section{Wog suppressed PC cell stem cell-like transition and mesenchymal transition}

Then, the influences of Wog on PC cell stem cell-like transition and mesenchymal transition were measured. As shown in Figure 3A, PANC-1 and SW1990 cells without Wog stimulation had a greater number of spheres and higher diameter of spheres than 25, 50, or $100 \mu \mathrm{M}$ Wog stimulation groups $(\mathrm{P}<0.05$ or $\mathrm{P}<0.01)$. Wog stimulation significantly reduced the number of spheres and the diameter of spheres. Figure $3 B$ showed that compared to PANC-1 and SW1990 cells without Wog stimulation, the PANC-1 and SW1990 cells in 25, 50, or $100 \mu \mathrm{M}$ Wog stimulation groups showed fewer mesenchymal transition properties, including elongated and spindlelike shapes. Besides, western blotting results showed that Wog stimulation noticeably reduced the protein levels of two stem cell marker proteins, CD44 and SOX2, and two mesenchymal transition marker proteins, $\mathrm{N}$-cad and MMP14 (Figure $3 C, 3 D, \mathrm{P}<0.05$ or $\mathrm{P}<0.01$ ). These outcomes suggested Wog suppressed PC cell stem cell-like transition and mesenchymal transition.

\section{Wog inactivated TRAF6/NF-кB/p65 patbway in PC cells}

We analyzed the differential expression of mRNAs between PC samples and normal tissues to identify the factors influencing $\mathrm{PC}$ development. The results were shown in Figure S1A,S1B. In addition, the KEGG and GO enrichment analysis was performed. The results of KEGGUP are displayed in Figure 4A, while KEGG-DOWN, GO$\mathrm{UP}$, and GO-DOWN were shown in Figure S1C-S1E. Considering the NF- $\mathrm{NB}$ pathway is an important signaling translation pathway involved in regulating tumor microenvironment (20) and the TNF signaling pathway was upregulated in PC (Figure $4 A$ ), the TRAF6/NF-кB/ 
A
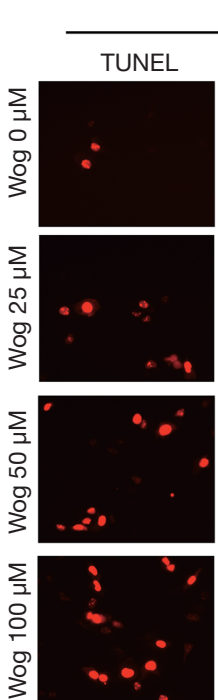

PANC-1
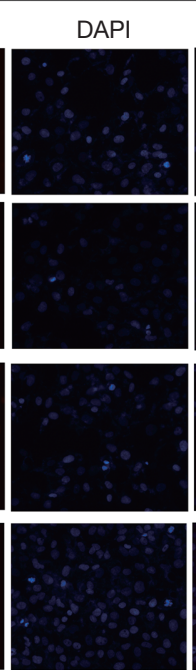

Merge
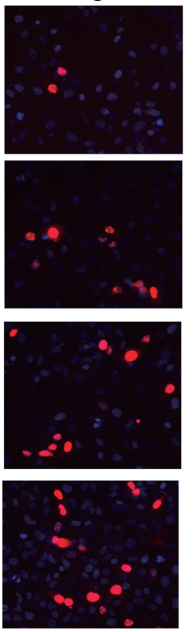
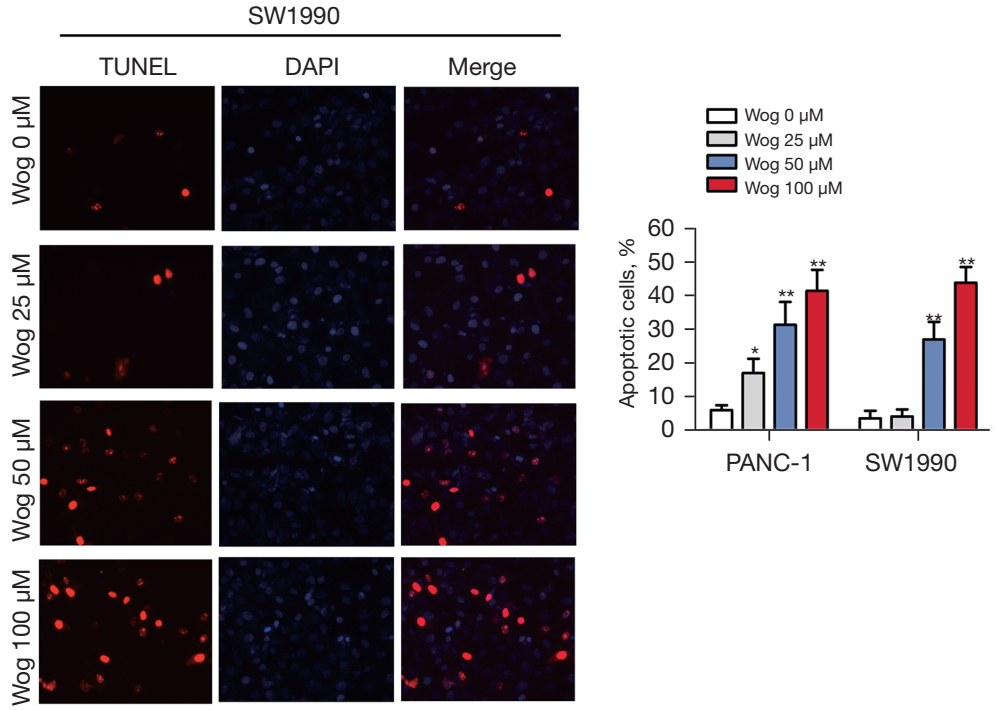

B

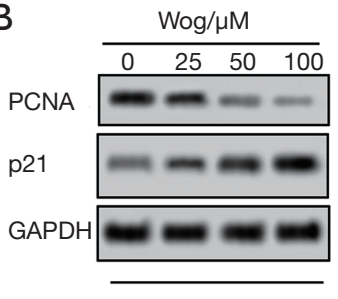

PANC-1
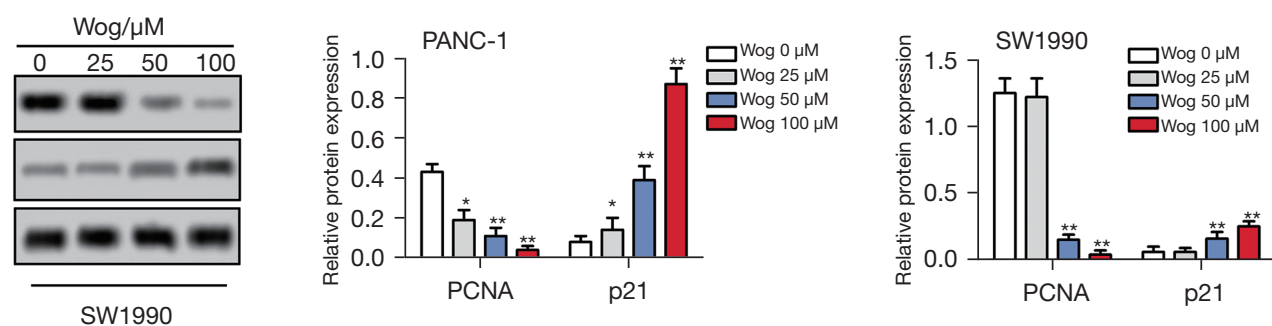

C
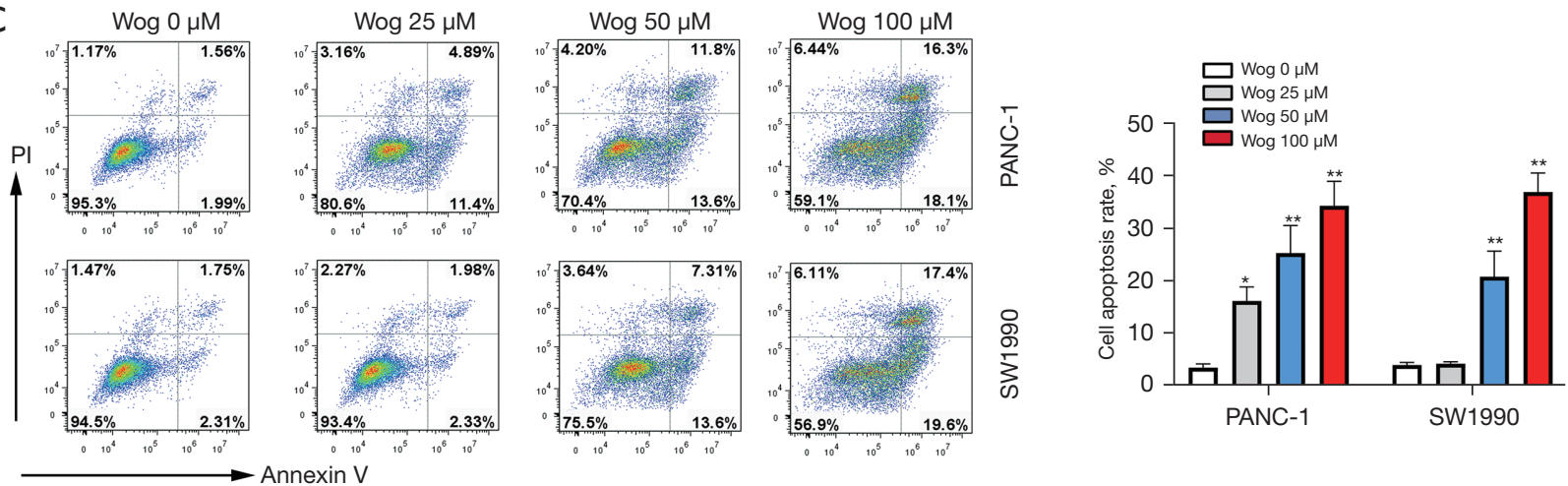

Figure 2 Wog inhibited PC cell proliferation and promoted cell apoptosis. Following 0, 25, 50, or $100 \mu M$ Wog stimulation (A), PANC1 and SW1990 cells' apoptosis were detected via TUNEL staining with One Step TUNEL Apoptosis Assay Kit (magnification: 200×). (B) Protein levels of PCNA and p21 in PANC-1 and SW1990 cells were evaluated via western blotting. (C) Cell apoptosis was analyzed by flow cytometry. ${ }^{*} \mathrm{P}<0.05$ or ${ }^{* *} \mathrm{P}<0.01$ vs. $0 \mu \mathrm{M}$ Wog stimulation group. $\mathrm{PC}$, pancreatic cancer.

p65 pathway was selected to study whether Wog exhibits anti-PC activity via modulating the TRAF6/NF- $\kappa \mathrm{B} /$ p65 pathway. Figure $4 B, 4 C$ illustrated that those different concentrations of Wog stimulation remarkably lowered the IL- $6, T N F-\alpha$, and IL-1 $\beta$ levels in the culture supernatant of
PANC- 1 and SW1990 cells $(\mathrm{P}<0.05$ or $\mathrm{P}<0.01)$. Figure $4 D$ presented that Wog stimulation reduced the protein levels of TRAF6, TAK1, p-IKK $\beta / \mathrm{IKK} \beta$, p-P65/P65, and VCAM1 in PANC-1 and SW1990 cells. Moreover, TRAF6 activator IL-1 $\beta$ was used to further evaluate whether Wog functioned 
A
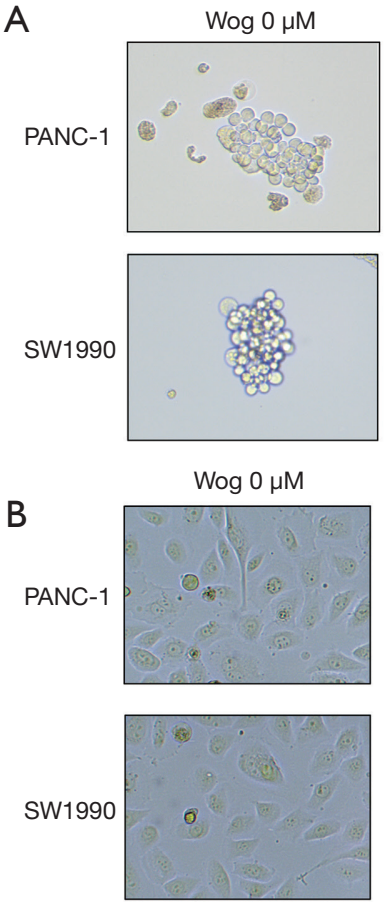
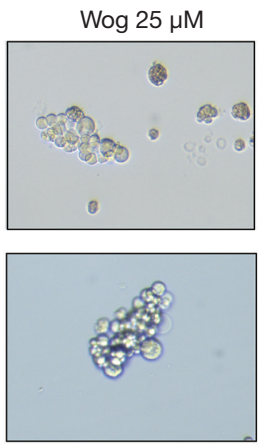

Wog $25 \mu \mathrm{M}$
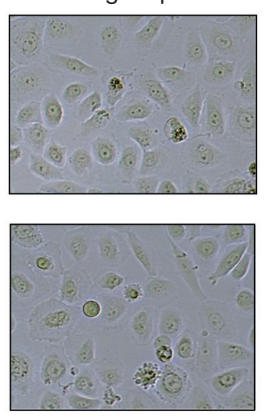
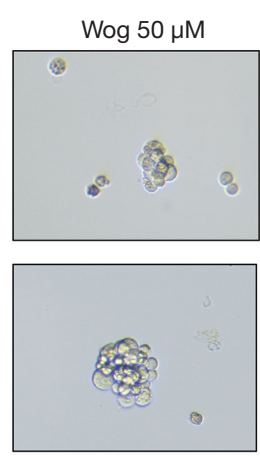

Wog $50 \mu \mathrm{M}$
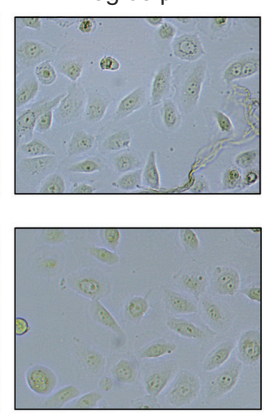

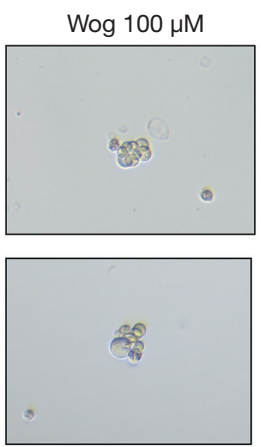

Wog $100 \mu \mathrm{M}$
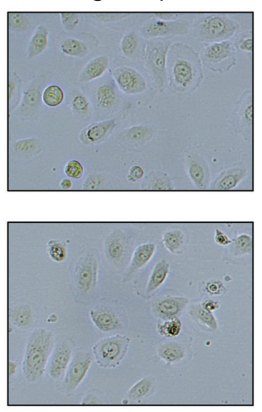
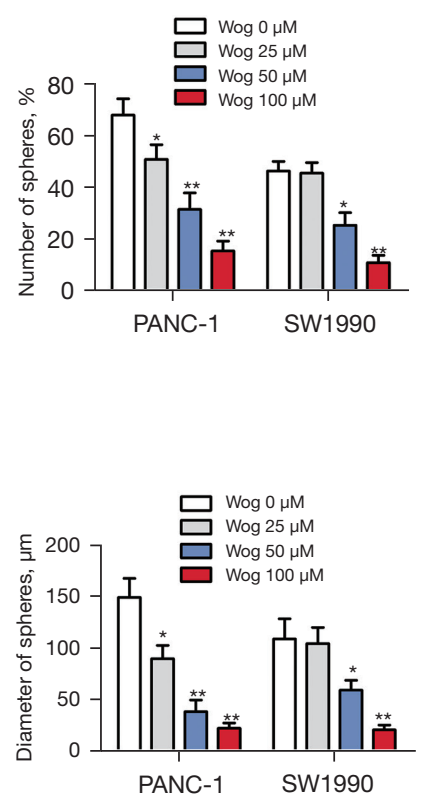

C

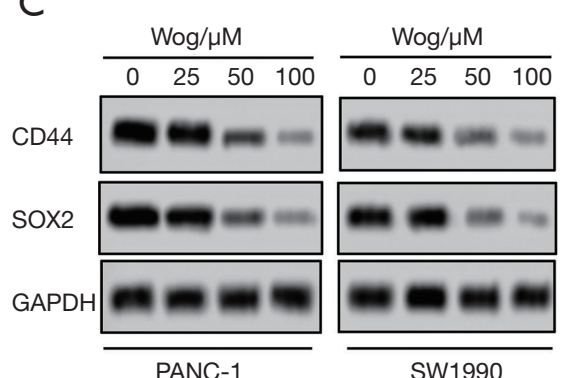

D

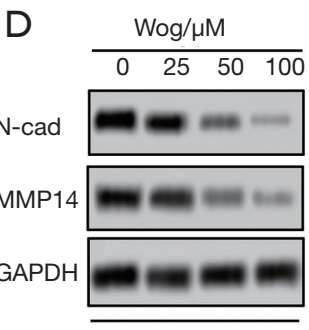

PANC-1

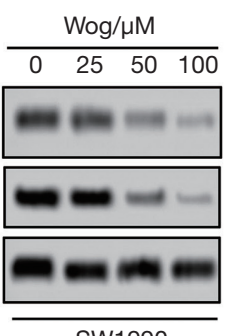

SW1990

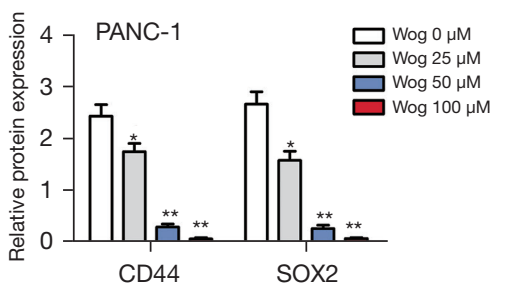

PANC-1

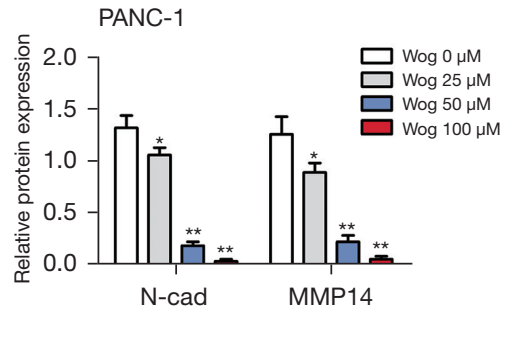

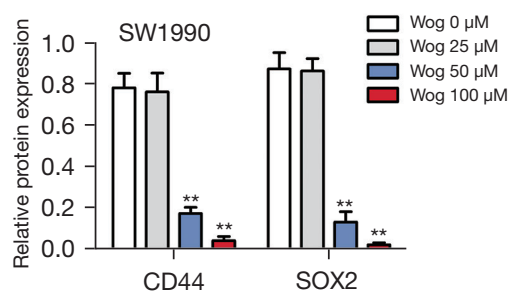

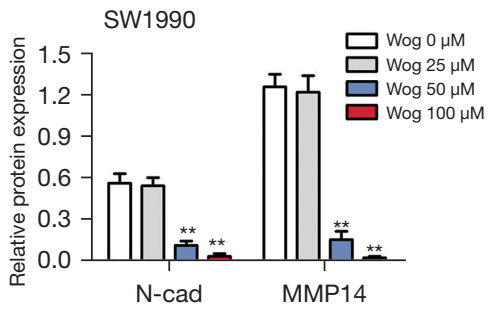

Figure 3 Wog suppressed PC cell stem cell-like transition and mesenchymal transition. Following 0, 25, 50 or $100 \mu M$ Wog stimulation, (A) the stem cell-like transition of PANC-1 and SW1990 cells were detected via cell spheres assay (magnification: 100x), (B) the mesenchymal transition of PANC-1 and SW1990 cells were evaluated under a microscope (magnification: 200x), (C,D) the protein levels of CD44, SOX2, $\mathrm{N}$-cad and MMP14 in PANC-1 and SW1990 cells were detected via western blotting. ${ }^{*} \mathrm{P}<0.05$ or ${ }^{* *} \mathrm{P}<0.01$ vs. $0 \mu M$ Wog stimulation group. PC, pancreatic cancer. 

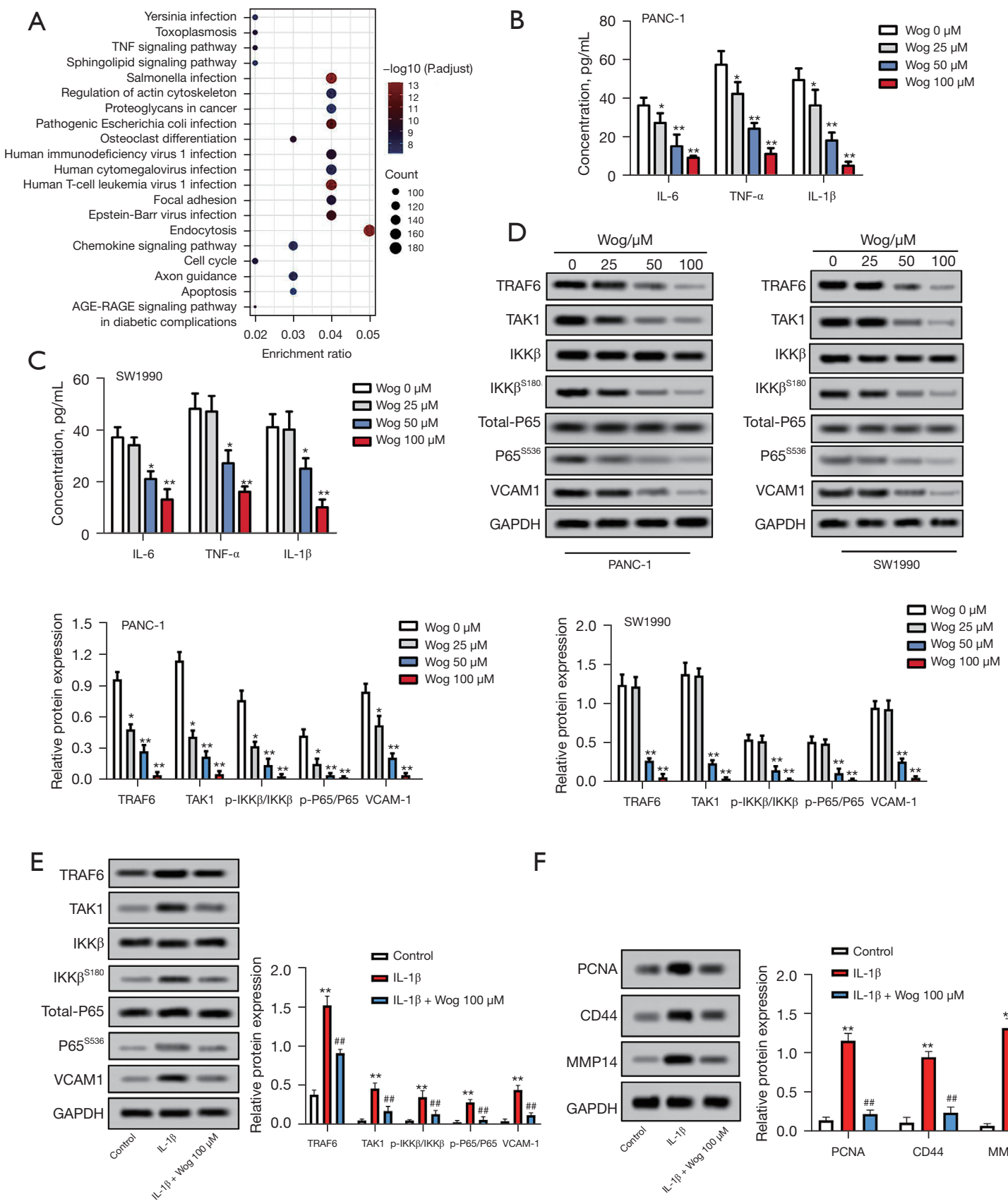

$\mathrm{F}$

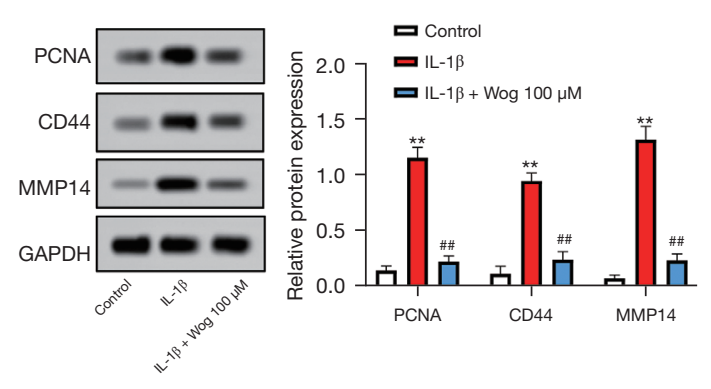

Figure 4 Wog inactivated TRAF6/NF- $\kappa \mathrm{B} / \mathrm{p} 65$ pathway in PC cells. (A) Bioinformatics analysis was conducted to identify the factors influencing PC progression. The result of KEGG-UP was shown. (B,C) Following 0, 25, 50, or $100 \mu \mathrm{M}$ Wog stimulation, the concentrations of IL-6, TNF- $\alpha$, and IL-1 $\beta$ levels in the culture supernatant of PANC-1 and SW1990 cells were measured via ELISA. (D) Following 0, 25, 50, or $100 \mu M$ Wog stimulation, the protein levels of TRAF6, TAK1, p-IKK $\beta /$ IKK $\beta$, p-P65/P65, and VCAM1 in PANC-1 and SW1990 cells were detected via western blotting. (E) PANC-1 cells were treated with $20 \mathrm{ng} / \mathrm{mL}$ IL-1 (TRAF6 activator) with or without $100 \mu \mathrm{M}$ Wog, and the protein levels of TRAF6, TAK1, p-IKK $/ \mathrm{IKK} \beta$, p-P65/P65, and VCAM1 were assayed by western blotting. (F) The levels of PCNA, CD44, and MMP14 were determined in PANC-1 cells under different treatments. ${ }^{*} \mathrm{P}<0.05$ or ${ }^{* *} \mathrm{P}<0.01$ vs. $0 \mu M$ Wog stimulation group or Control group, ${ }^{\# \#} \mathrm{P}<0.01$ vs. IL-1 13 group. TRAF6, tumor necrosis factor receptor-associated factor 6; NF- $\mathrm{kB}$, nuclear factor-kappa B; PC, pancreatic cancer. 
via the TRAF6/NF- $\kappa \mathrm{B} / \mathrm{p} 65$ pathway, the results showed that $100 \mu \mathrm{M}$ Wog treatment partially attenuated the influences of IL- $1 \beta$ stimulation on TRAF6, TAK1, p-IKK $\beta / \mathrm{IKK} \beta$, p-P65/P65, VCAM1, PCNA, CD44, and MMP14 protein levels in PANC-1 cells (Figure 4E,4F). These outcomes suggested that Wog exerted anti-PC activity might be via inactivating the TRAF6/NF- $\mathrm{kB} / \mathrm{p} 65$ pathway.

\section{TRAF6, VCAM1, CD44, and MMP14 were related to PC survival and prognosis}

Subsequently, bioinformatics analysis was conducted to explore TRAF6, VCAM1, CD44, and MMP14 expression in PC tissues, and the influences of TRAF6, VCAM1, CD44, and MMP14 expressions on PC survival and prognosis. Figure $5 \mathrm{~A}$ showed that compared to normal tissues, the expressions of TRAF6, VCAM1, CD44, and MMP14 were all increased in $\mathrm{PC}$ tissues $(\mathrm{P}<0.01)$. Figure $5 B$ showed that patients with high expressions of TRAF6, VCAM1, CD44, or MMP14 had a short overall survival probability. The result of univariate Cox regression analysis showed that the TRAF6, VCAM1, CD44, MMP14, age, pN stage, Grade, and Radiation therapy were significant factors affecting the prognosis of $\mathrm{PC}$ patients (Figure $5 C, \mathrm{P}<0.05$ or $\mathrm{P}<0.01)$. The multivariate Cox regression analysis result illustrated that age, $\mathrm{pN}$ stage, and radiation therapy were independent factors affecting PC prognosis (Figure 5 D, $\mathrm{P}<0.05)$. Besides, a nomogram was used to predict the 1 -year survival probability of PC patients (Figure 5E). These outcomes suggested that TRAF6, VCAM1, CD44, and MMP14 were related to PC survival and prognosis. Inhibition of TRAF6, VCAM1, CD44, and MMP14 will be of significant value for improving PC survival and prognosis.

\section{Wog exerted anti-PC activity via modulating TRAF6}

Finally, TRAF6 was overexpressed in PANC-1 cells to confirm the role of TRAF6 in the anti-PC activity of Wog. Figure $6 A, 6 B$ showed that the protein levels of TRAF6, p-P65/P65, VCAM1, CD44, and MMP14 were all increased in PANC-1 cells after TRAF6 overexpression $(\mathrm{P}<0.05$ or $\mathrm{P}<0.01) .100 \mu \mathrm{M}$ Wog treatment partially reversed the influences of TRAF6 overexpression on TRAF6, TAK1, p-IKK $\beta / I K K \beta$, p-P65/P65, VCAM1, CD44, and MMP14 protein levels in $\mathrm{PANC}-1$ cells $(\mathrm{P}<0.05$ or $\mathrm{P}<0.01)$. Figure $6 C, 6 D$ showed that TRAF6 overexpression promoted the PC cell stem cell-like transition and mesenchymal transition $(\mathrm{P}<0.05)$, while Wog treatment eliminated the effects of TRAF6 overexpression $(\mathrm{P}<0.05)$. In addition, Figure $6 E-6 G$ showed that compared to the mice in the control group, the mice in the TRAF6 overexpression group had greater tumor volume and heavier tumor weight $(\mathrm{P}<0.05$ or $\mathrm{P}<0.01)$. Wog treatment notably reduced the tumor volume and weight $(\mathrm{P}<0.05$ or $\mathrm{P}<0.01)$. The immunohistochemistry results in Figure 6H,6I illustrated that TRAF6 overexpression raised the TRAF6 and VCAM1 expressions in the cytoplasm of PC cells, as well as elevated the CD44 and MMP14 expressions in the cell membrane of PC cells $(\mathrm{P}<0.01)$. Wog treatment noticeably reversed the effects of TRAF6 overexpression on TRAF6, VCAM1, CD44, and MMP14 expressions $(\mathrm{P}<0.01)$. These outcomes further affirmed that Wog exerted anti-PC activity via modulating TRAF6.

\section{Discussion}

Although the diagnosis and therapy of PC have made some progress in recent years, the prognosis of $\mathrm{PC}$ is still insufficient $(3,21)$. As the major bioactive ingredient of Scutellaria baicalensis Georgi, Wog shows excellent anticancer activity for many types of human cancers $(8,9,12)$. In the current research, we discovered that Wog inhibited PC cell proliferation and promoted cell apoptosis. The expressions of two key proteins involved in cell proliferation, PCNA (22) and p21 (23), were notably decreased after Wog stimulation. These findings verified that Wog also exerted an anti-cancer effect on PC.

Tumor recurrence and metastasis are two principal reasons for the poor prognosis of PC (4). We also found that Wog suppressed PC cell stem cell-like transition and mesenchymal transition in this research. CD44 protein is a group of multi-molecular forms of integral membrane proteins that mediate the interaction between cells or cells and the extracellular matrix (24). It is usually highly expressed on the surface of cancer stem cells and participates in regulating cancer stemness, including selfrenewal, recurrence, and metastasis (25). As an important transcription factor in cells, SOX2 protein contains a domain that specifically binds to DNA (high mobility group protein, HGM) (26). Earlier literature reported that SOX2 had stem cell characteristics and regulated cancer stem cells (27).

Herreros-Villanueva et al. (28) discovered that SOX2 facilitated dedifferentiation of PC cells and endowed PC cells to stem cell-like properties. Besides, $\mathrm{N}$-cad protein is a key EMT marker protein (29). The increased expression 

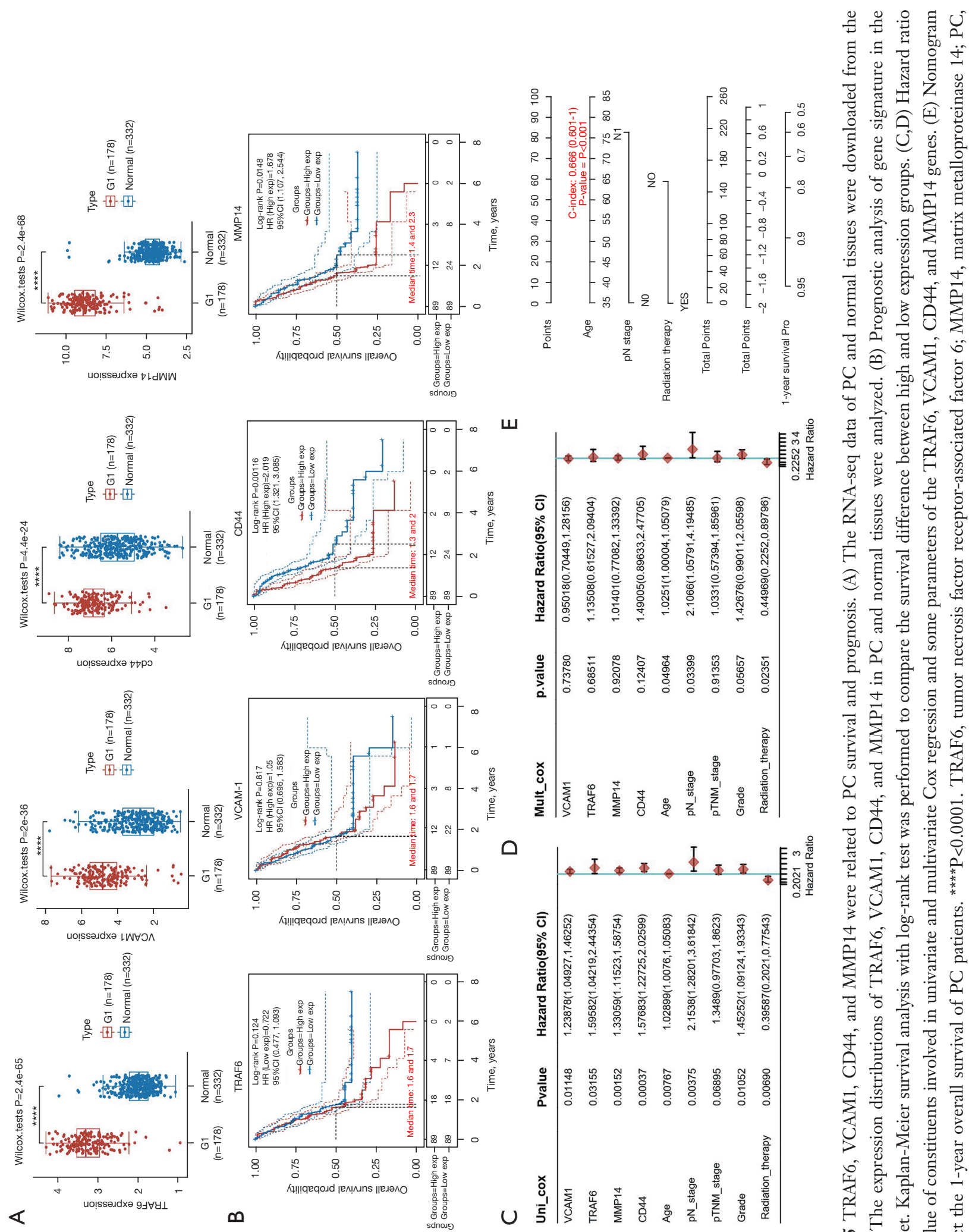

.

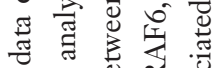

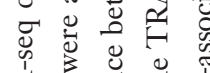

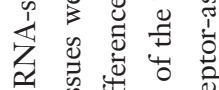

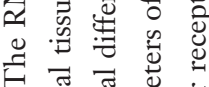

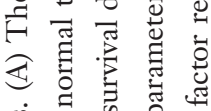

它

Do

艺 $\Xi$ 言

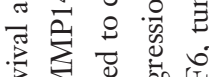

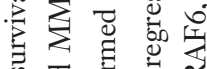

论

○ 求㟔

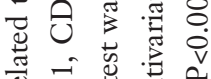

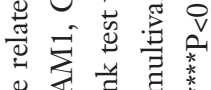

今心

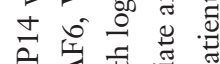

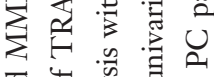

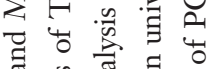

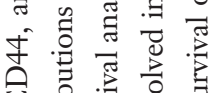

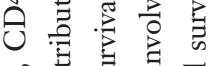

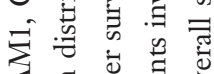

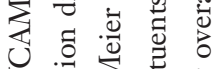

$>$.

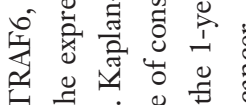

in

产芯芯芯芯 
A

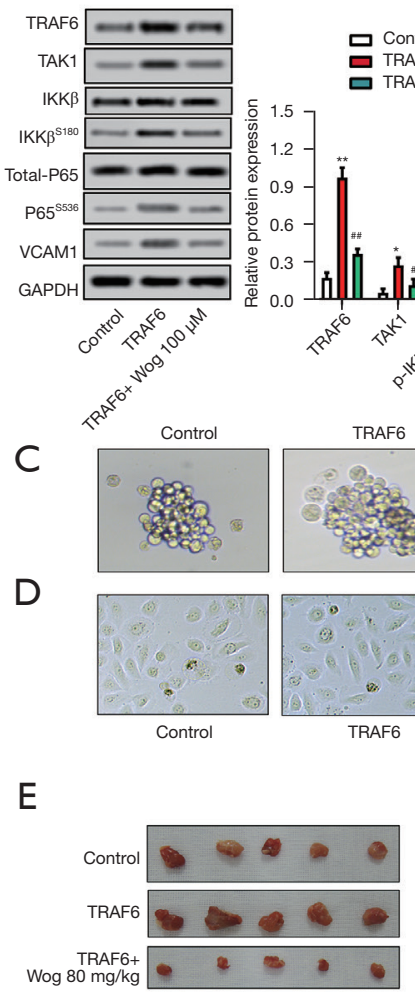

$\mathrm{H}$
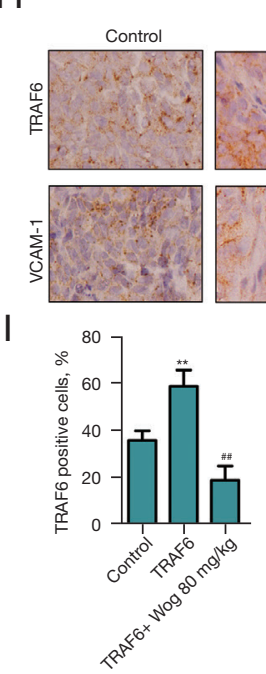

TRAF6

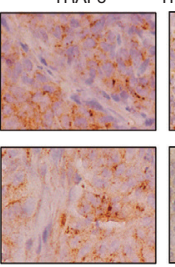

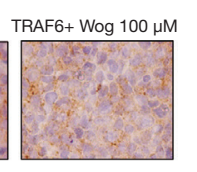

$\mathrm{F}_{3000}$
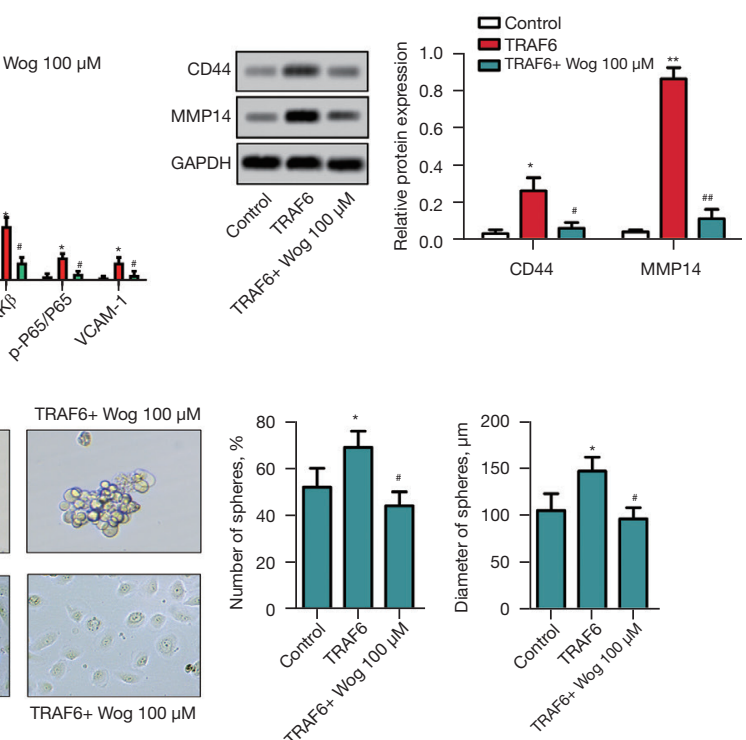

.
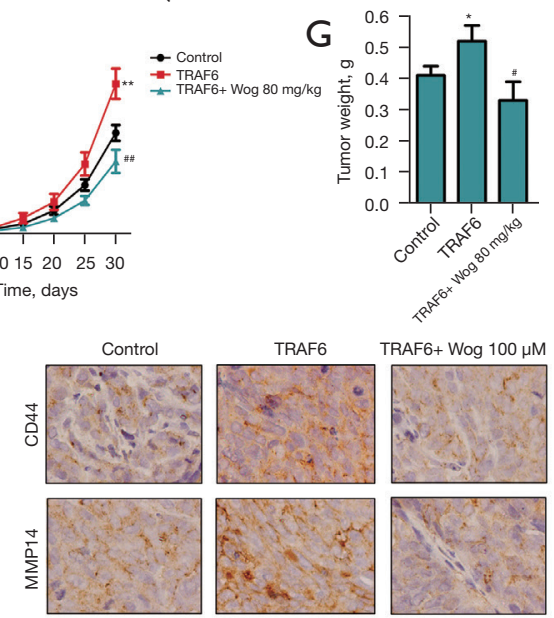

TRAF6+ Wog $100 \mu \mathrm{M}$
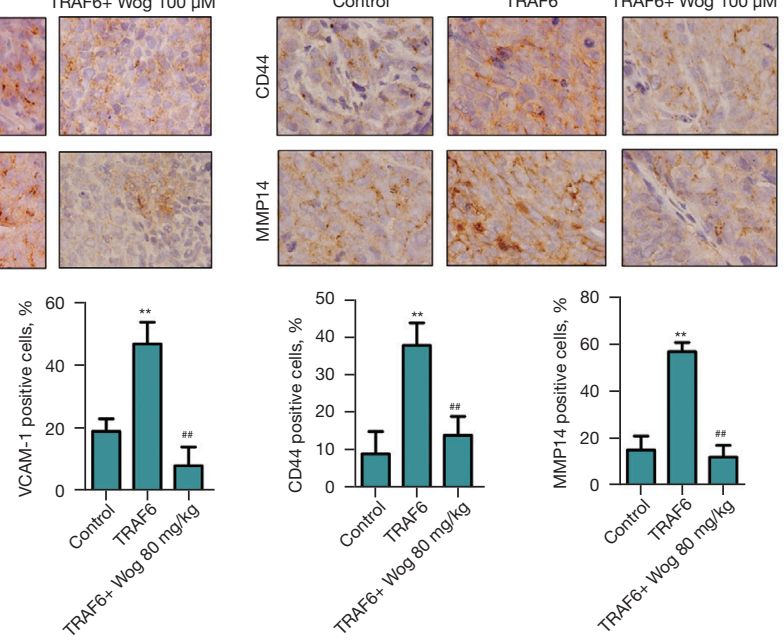

Figure 6 Wog exerted anti-PC activity via modulating TRAF6. TRAF6 overexpression plasmid was transfected into PANC-1 cells. Following $100 \mu \mathrm{M}$ Wog stimulation (A and B), the protein levels of TRAF6, TAK1, p-IKK $\beta / \mathrm{IKK} \beta$, p-P65/P65, VCAM1, CD44, and MMP14 in cells were measured via western blotting. (C) The stem cell-like transition of PANC-1 cells was observed under a microscope (magnification: 100x). (D) Mesenchymal transition of PANC-1 cells was detected under a microscope (magnification: 200x). PC xenograft animal model was established and subjected to appropriate treatment. (E-G) The tumor picture, volume growth curve, and tumor weight were displayed. (H and I) Immunohistochemistry was conducted to detect TRAF6 and VCAM1 expressions in the cytoplasm, CD44 and MMP14 expressions in the cell membrane (magnification: $400 \times$ ). ${ }^{*} \mathrm{P}<0.05$ or ${ }^{* *} \mathrm{P}<0.01$ vs. Control group, ${ }^{\#} \mathrm{P}<0.05$ or ${ }^{\# \#} \mathrm{P}<0.01$ vs. TRAF6 group. TRAF6, tumor necrosis factor receptor-associated factor 6; MMP14, matrix metalloproteinase 14; PC, pancreatic cancer. 
of N-cad usually is the activation of EMT (29). MMP14 is an important member of the MMPs family (30). Numerous studies have shown that the ability of tumor cells to invade and metastasize is closely related to the ability of MMPs, including MMP14, to degrade the extracellular matrix and basement $(31,32)$. We revealed that Wog lowered the protein levels of CD44, SOX2, N-cad, and MMP14 in PC cells, which implied that Wog suppressed PC cell stem celllike transition, and mesenchymal transition might be via reducing these proteins expressions.

In recent years, more and more research has confirmed that tumor microenvironment induced by interactions between tumor cells and surrounding microenvironment (comprising surrounding blood vessels, immune cells, fibroblasts, bone-marrow-derived inflammatory cells, various signal molecules, and extracellular matrix) is vital for tumor development, including PC $(33,34)$. The characteristics of pancreatic cancer microenvironment include desmoplasia and immunosuppression, mainly involving in PC cells, regulatory $\mathrm{T}$ cells, myeloid-derived suppressor cells, tumor-associated macrophages and pancreatic stellate cells (5). Recently, the combinations of different therapies were carried out to increase antitumour efficacy or reverse immunodeficiencies, for example, targeting cancer cells and the stroma, reversing suppressive immune reactions and enhancing antitumour reactivity (35). Some literature reported that PC stem cells could alter the tumor microenvironment to help maintain cell stemness. Stromal cells in the tumor microenvironment could help maintain the number of PC stem cells $(5,36,37)$. Moreover, earlier studies verified that the tumor microenvironment participated in PC metastasis by promoting angiogenesis, lymphangiogenesis, EMT, migration, and invasion (5). In the current research, we found that the TNF signaling pathway was upregulated in PC by bioinformatics analysis. $\mathrm{NF}-\kappa \mathrm{B}$ is widely used by eukaryotic cells as a gene regulator to control cell proliferation and survival (38).

What is more, the NF- $\kappa \mathrm{B}$ pathway is demonstrated to play a key role in multiple cancers initiation and progression (39). In the last few years, increasing literature reported that the $\mathrm{NF}-\kappa \mathrm{B}$ pathway also regulates the tumor microenvironment $(20,40)$. TRAF6 is regulator of NF- $\kappa$ B signaling. Rong et al. (18) found that TRAF6 expression was elevated in PC tissues, and its overexpression could promote $\mathrm{PC}$ cell growth and metastasis both in vitro and in vivo. Moreover, TRAF6 facilitated the migration and colony formation of $\mathrm{PC}$ cells via regulating YAP signaling by promoting the ubiquitination and degradation of MST1 (41).
TRAF6 was also related to gemcitabine resistance in PC (42). Importantly, it was reported that TRAF6 could regulate melanoma's tumor microenvironment (19). By using bioinformatics analysis, we found that TRAF6, VCAM1, CD44, and MMP14 were up regulated in PC tissues and they were related to the poor prognosis of PC patients. Wog is confirmed to exert anti-cancer activity via modulating the NF- $\kappa$ B pathway (13). Thus, here, we want to know whether Wog shows anti-cancer activity in $\mathrm{PC}$ through regulating the TRAF6/NF-кB/p65 pathway. We discovered that Wog reduced the TRAF6, TAK1, p-IKK $\beta / \mathrm{IKK} \beta$, p-P65/P65, and VCAM1 [a member of the immunoglobulin superfamily that joins in PC progression (43)] protein levels in PC cells, accompanied by decreased productions of IL- 6 , TNF- $\alpha$, and IL-1 $\beta$. Besides, by overexpressing TARF6 and stimulation with IL-1 $\beta$ (TARF6 activator) in PC cells, we confirmed that Wog exerted anti-PC cell stem cell-like transition and mesenchymal transition via modulating TRAF6. In vivo, the experiment also verified that Wog reversed the TRAF6 overexpression-induced PC tumor growth. Additonally, Wog inhibited the levels of TRAF6, VCAM1, CD44, and MMP14 both in PC cells and tumor tissues. These findings suggested that Wog played anti-PC activity via modulating the TRAF6 mediated-tumor microenvironment of PC.

This research, taken together, affirmed the anti-PC activity of Wog. Wog inhibited PC cell proliferation and promoted cell apoptosis. Wog suppressed the TRAF6 mediated-tumor microenvironment of PC, limiting inflammation, PC cell stem cell-like transition, and mesenchymal transition. However, considering that tumor microenvironment contains many aspects, the effect of Wog on the PC microenvironment needs further investigation.

\section{Acknowledgments}

Funding: This research received help from the National Natural Science Foundation of China (No. 81873589).

\section{Footnote}

Reporting Checklist: The authors have completed the ARRIVE reporting checklist. Available at https://dx.doi. org/10.21037/atm-21-4164

Data Sharing Statement: Available at https://dx.doi. org/10.21037/atm-21-4164

Conflicts of Interest: All authors have completed the ICMJE 
uniform disclosure form (available at https://dx.doi. org/10.21037/atm-21-4164). The authors have no conflicts of interest to declare.

Ethical Statement: The authors are accountable for all aspects of the work in ensuring that questions related to the accuracy or integrity of any part of the work are appropriately investigated and resolved. The study was conducted in accordance with the Declaration of Helsinki (as revised in 2013). Experiments were performed under a project license [No.: SYXK(Xiang)2017-0002] granted by the Third Xiangya Hospital, Central South University, in compliance with China guidelines for the care and use of animals.

Open Access Statement: This is an Open Access article distributed in accordance with the Creative Commons Attribution-NonCommercial-NoDerivs 4.0 International License (CC BY-NC-ND 4.0), which permits the noncommercial replication and distribution of the article with the strict proviso that no changes or edits are made and the original work is properly cited (including links to both the formal publication through the relevant DOI and the license). See: https://creativecommons.org/licenses/by-nc-nd/4.0/.

\section{References}

1. Yadav D, Lowenfels AB. The epidemiology of pancreatitis and pancreatic cancer. Gastroenterology 2013;144:1252-61.

2. Siegel RL, Miller KD, Jemal A. Cancer statistics, 2020. CA Cancer J Clin 2020;70:7-30.

3. Wei L, Wen JY, Chen J, et al. Oncogenic ADAM28 induces gemcitabine resistance and predicts a poor prognosis in pancreatic cancer. World J Gastroenterol 2019;25:5590-603.

4. McGuigan A, Kelly P, Turkington RC, et al. Pancreatic cancer: A review of clinical diagnosis, epidemiology, treatment and outcomes. World J Gastroenterol 2018;24:4846-61.

5. Ren B, Cui M, Yang G, et al. Tumor microenvironment participates in metastasis of pancreatic cancer. Mol Cancer 2018;17:108.

6. Dougan SK. The Pancreatic Cancer Microenvironment. Cancer J 2017;23:321-5.

7. Yao Y, Zhao K, Yu Z, et al. Wogonoside inhibits invasion and migration through suppressing TRAF2/4 expression in breast cancer. J Exp Clin Cancer Res 2017;36:103.

8. Wei C, Jing J, Zhang Y, et al. Wogonoside Inhibits
Prostate Cancer Cell Growth and Metastasis via Regulating Wnt/ $\beta$-Catenin Pathway and EpithelialMesenchymal Transition. Pharmacology 2019;104:312-9.

9. Chen $\mathrm{S}, \mathrm{Wu} Z, \mathrm{Ke} Y$, et al. Wogonoside inhibits tumor growth and metastasis in endometrial cancer via ER stressHippo signaling axis. Acta Biochim Biophys Sin (Shanghai) 2019;51:1096-105.

10. Hu XM, Xiang JJ, Xiao BL, et al. Wogonoside promotes apoptosis in gastric cancer AGS and SGC-7901 cells through induction of mitochondrial dysfunction and endoplasmic reticulum stress. FEBS Open Bio 2019;9:1469-76.

11. Wang Y, Yin RF, Teng JS. Wogonoside induces cell cycle arrest and mitochondrial mediated apoptosis by modulation of Bcl-2 and Bax in osteosarcoma cancer cells. Int J Clin Exp Pathol 2015;8:63-72.

12. Luo M, Mo J, Yu Q, et al. Wogonoside induces apoptosis in human non-small cell lung cancer A549 cells by promoting mitochondria dysfunction. Biomed Pharmacother 2018;106:593-8.

13. Sun Y, Zhao Y, Wang X, et al. Wogonoside prevents colitis-associated colorectal carcinogenesis and colon cancer progression in inflammation-related microenvironment via inhibiting NF- B activation through PI3K/Akt pathway. Oncotarget 2016;7:34300-15.

14. Wang X, Chang Y, Gao M, et al. Wogonoside Attenuates Cutaneous Squamous Cell Carcinoma by Reducing Epithelial-Mesenchymal Transition/Invasion and Cancer Stem-Like Cell Property. Onco Targets Ther 2020;13:10097-109.

15. Yang WL, Wang J, Chan CH, et al. The E3 ligase TRAF6 regulates Akt ubiquitination and activation. Science 2009;325:1134-8.

16. Li J, Liu N, Tang L, et al. The relationship between TRAF6 and tumors. Cancer Cell Int 2020;20:429.

17. Wang Z, Liu Y, Huang S, et al. TRAF6 interacts with and ubiquitinates PIK3CA to enhance PI3K activation. FEBS Lett 2018;592:1882-92.

18. Rong Y, Wang $\mathrm{D}, \mathrm{Wu} \mathrm{W}$, et al. TRAF6 is over-expressed in pancreatic cancer and promotes the tumorigenicity of pancreatic cancer cells. Med Oncol 2014;31:260.

19. Guo Y, Zhang X, Zeng W, et al. TRAF6 Activates Fibroblasts to Cancer-Associated Fibroblasts through FGF19 in Tumor Microenvironment to Benefit the Malignant Phenotype of Melanoma Cells. J Invest Dermatol 2020;140:2268-2279.e11.

20. Kemp DM, Pidich A, Larijani M, et al. Ladarixin, a dual CXCR1/2 inhibitor, attenuates experimental melanomas 
harboring different molecular defects by affecting malignant cells and tumor microenvironment. Oncotarget 2017;8:14428-42.

21. Rofi E, Vivaldi C, Del Re M, et al. The emerging role of liquid biopsy in diagnosis, prognosis and treatment monitoring of pancreatic cancer. Pharmacogenomics 2019;20:49-68.

22. Juríková M, Danihel L, Polák Š , et al. Ki67, PCNA, and MCM proteins: Markers of proliferation in the diagnosis of breast cancer. Acta Histochem 2016;118:544-52.

23. Venu A, Archana B, Kanumuri R, et al. Clinical Evaluation of P21 Activated Kinase 1 (PAK1) Activation in Gliomas and Its Effect on Cell Proliferation. Cancer Invest 2021;39:98-113.

24. Prochazka L, Tesarik R, Turanek J. Regulation of alternative splicing of CD44 in cancer. Cell Signal 2014;26:2234-9.

25. Wang L, Zuo X, Xie K, et al. The Role of CD44 and Cancer Stem Cells. Methods Mol Biol 2018;1692:31-42.

26. Chaudhary S, Islam Z, Mishra V, et al. Sox2: A Regulatory Factor in Tumorigenesis and Metastasis. Curr Protein Pept Sci 2019;20:495-504.

27. Schaefer T, Lengerke C. SOX2 protein biochemistry in stemness, reprogramming, and cancer: the PI3K/AKT/ SOX2 axis and beyond. Oncogene 2020;39:278-92.

28. Herreros-Villanueva M, Zhang JS, Koenig A, et al. SOX2 promotes dedifferentiation and imparts stem celllike features to pancreatic cancer cells. Oncogenesis 2013;2:e61.

29. Mrozik KM, Blaschuk OW, Cheong CM, et al. N-cadherin in cancer metastasis, its emerging role in haematological malignancies and potential as a therapeutic target in cancer. BMC Cancer 2018;18:939.

30. Cui N, Hu M, Khalil RA. Biochemical and Biological Attributes of Matrix Metalloproteinases. Prog Mol Biol Transl Sci 2017;147:1-73.

31. Kessenbrock K, Plaks V, Werb Z. Matrix metalloproteinases: regulators of the tumor microenvironment. Cell 2010;141:52-67.

32. Winer A, Adams S, Mignatti P. Matrix Metalloproteinase
Cite this article as: Huang $\mathrm{H}, \mathrm{Li} \mathrm{X}, \mathrm{Yu} \mathrm{L}$, Liu L, Zhu H, Cao W, Sun Z, Yu X. Wogonoside inhibits TNF receptorassociated factor 6 (TRAF6) mediated-tumor microenvironment and prognosis of pancreatic cancer. Ann Transl Med 2021;9(18):1460. doi: 10.21037/atm-21-4164
Inhibitors in Cancer Therapy: Turning Past Failures Into Future Successes. Mol Cancer Ther 2018;17:1147-55.

33. Arneth B. Tumor Microenvironment. Medicina (Kaunas) 2019;56:15.

34. Ligorio M, Sil S, Malagon-Lopez J, et al. Stromal Microenvironment Shapes the Intratumoral Architecture of Pancreatic Cancer. Cell 2019;178:160-175.e27.

35. Fan JQ, Wang MF, Chen HL, et al. Current advances and outlooks in immunotherapy for pancreatic ductal adenocarcinoma. Mol Cancer 2020;19:32.

36. Abel EV, Kim EJ, Wu J, et al. The Notch pathway is important in maintaining the cancer stem cell population in pancreatic cancer. PLoS One 2014;9:e91983.

37. Lonardo E, Frias-Aldeguer J, Hermann PC, et al. Pancreatic stellate cells form a niche for cancer stem cells and promote their self-renewal and invasiveness. Cell Cycle 2012;11:1282-90.

38. Mitchell S, Vargas J, Hoffmann A. Signaling via the NFאB system. Wiley Interdiscip Rev Syst Biol Med 2016;8:227-41.

39. Hoesel B, Schmid JA. The complexity of NF- $\kappa$ B signaling in inflammation and cancer. Mol Cancer 2013;12:86.

40. Zhuang X, Li X, Zhang J, et al. Conditioned medium mimicking the tumor microenvironment augments chemotherapeutic resistance via ataxia-telangiectasia mutated and nuclear factor- $\kappa \mathrm{B}$ pathways in gastric cancer cells. Oncol Rep 2018;40:2334-42.

41. Li JA, Kuang T, Pu N, et al. TRAF6 regulates YAP signaling by promoting the ubiquitination and degradation of MST1 in pancreatic cancer. Clin Exp Med 2019;19:211-8.

42. Meng Q, Liang C, Hua J, et al. A miR-146a-5p/ TRAF6/NF-kB p65 axis regulates pancreatic cancer chemoresistance: functional validation and clinical significance. Theranostics 2020;10:3967-79.

43. Sano M, Takahashi R, Ijichi H, et al. Blocking VCAM1 inhibits pancreatic tumour progression and cancerassociated thrombosis/thromboembolism. Gut 2021;70:1713-23.

(English Language Editor: J. Chapnick) 


\section{Supplementary}

A

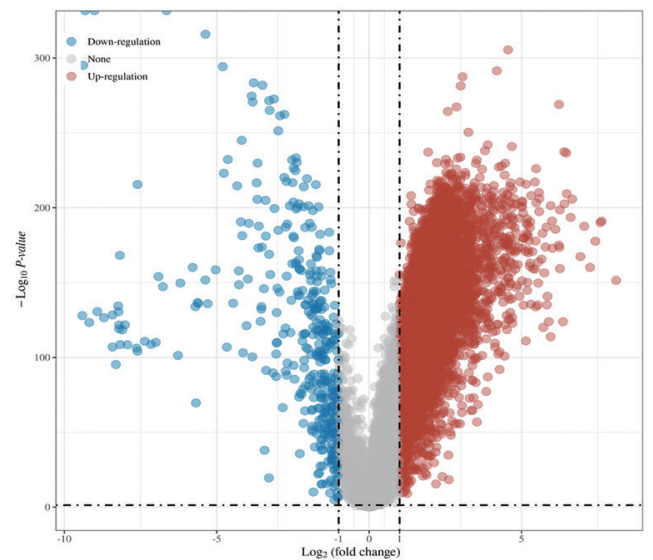

C

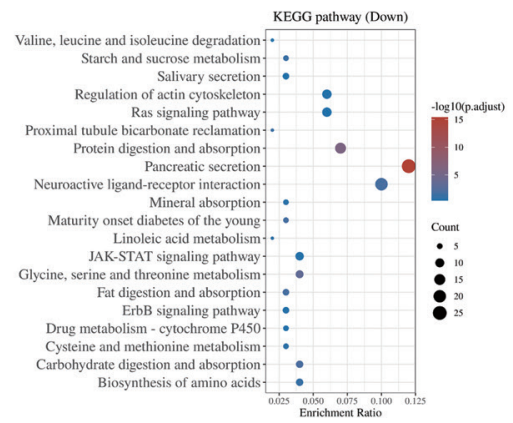

B

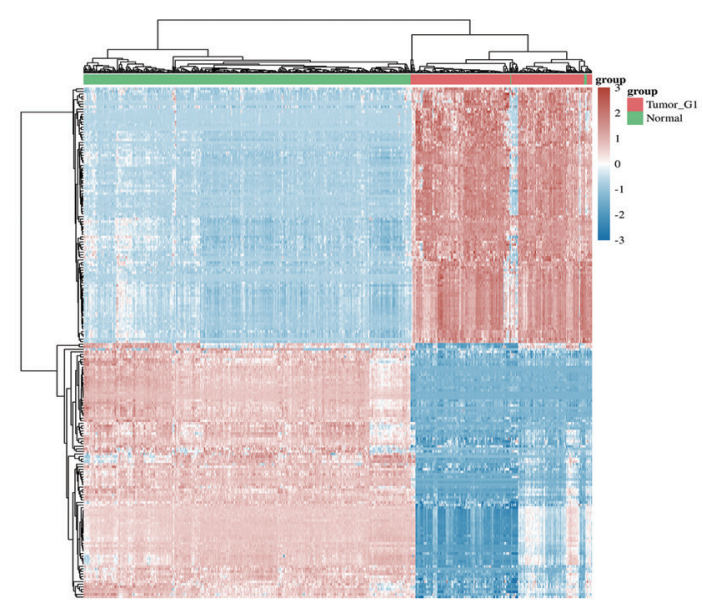

E

Figure S1 The differential expression of mRNAs between PC samples and normal tissues was analyzed. (A) Volcano plots were constructed using fold-change values and adjusted P. The red point in the plot is the over-expressed mRNAs, and the blue point shows the downexpressed mRNAs with statistical significance. (B) Hierarchical clustering analysis of mRNAs, which were differentially expressed between tumor and normal tissues. (C-E) The results of differentially expressed genes of KEGG-DOWN, GO-UP, and GO-DOWN. 